\title{
Stereotype susceptibility narrows the gender gap in imagined self-rotation performance
}

\author{
MARYJANE WRAGA and LAUREN DUNCAN \\ Smith College, Northampton, Massachusetts \\ EMILY C. JACOBS \\ University of California, Berkeley, California \\ MOLLY HELT \\ Smith College, Northampton, Massachusetts \\ and \\ JESSICA CHURCH \\ Washington University, St. Louis, Missouri
}

\begin{abstract}
Three studies examined the impact of stereotype messages on men's and women's performance of a mental rotation task involving imagined self-rotations. Experiment 1 established baseline differences between men and women; women made 12\% more errors than did men. Experiment 2 found that exposure to a positive stereotype message enhanced women's performance in comparison with that of another group of women who received neutral information. In Experiment 3, men who were exposed to the same stereotype message emphasizing a female advantage made more errors than did male controls, and the magnitude of error was similar to that for women from Experiment 1. The results suggest that the gender gap in mental rotation performance is partially caused by experiential factors, particularly those induced by sociocultural stereotypes.
\end{abstract}

The remarks of former Harvard President Lawrence Summers have reignited the debate on the nature of intelligence and its consequences for academic achievement in men and women (Ripley, 2005). Although traditional gender gaps in cognitive performance have diminished over past decades, one of the few exceptions to this trend involves mental rotation, a skill of spatial reasoning that is critical to success in academic fields such as mathematics and science (Feingold, 1988; Masters \& Sanders, 1993). Mental rotation tasks consistently yield the largest and most reliable gender differences of any cognitive task, with men's performance surpassing that of women by approximately $1 S D$ (Campos, Pérez-Fabello, \& GómezJuncal, 2004; Linn \& Petersen, 1985; Masters \& Sanders, 1993; Voyer, Voyer, \& Bryden, 1995).

A predominant explanation for the performance gap in mental rotation involves biological factors, such as differential hormonal levels (Geary, 1995; Kimura \& Hampson, 1994). However, studies exploring the impact of stereotypes on cognitive performance suggest that social factors might also play a role. For example, in comparison with men, women perform worse on math tests when they are reminded of gender differences in mathematical abilities (Spencer, Steele, \& Quinn, 1999). Steele and colleagues (Steele, 1997;

Address correspondence to M. Wraga, Department of Psychology, Smith College, Northampton, MA 01063 (e-mail: mwraga@smith.edu).
Steele, Spencer, \& Aronson, 2002) posited that stereotype threat - the fear of confirming a negative stereotype about a group to which one belongs - is responsible for such decrements in cognitive performance. Social psychologists have demonstrated the effects of stereotype threat on numerous other stigmatized groups, including African Americans (Steele \& Aronson, 1995), Asian Americans (Shih, Pittinsky, \& Ambady, 1999), and the elderly (Levy, 1996).

The stereotype-threat literature has yielded at least two other noteworthy findings. The first is that the cognitive performance of dominant groups, such as White men, may also be susceptible to stereotype messages (see, e.g., Aronson et al., 1999; Brown \& Josephs, 1999; Leyens, Désert, Croizet, \& Darcis, 2000). Aronson et al. found that White men who were exposed to the stereotype that Asian men outperform White men in mathematics performed significantly worse on a math exam than did a control group of White men for whom the stereotype was not mentioned. Leyens et al. found selective deficits in men's cognitive performance after exposure to the stereotype that men are relatively inefficient at processing affective information. Men made significantly more errors than did women on a subsequent lexical decision task involving affective processing; however, no differences were found between groups for nonaffective judgments, such as distinguishing between words and nonwords. Thus, men's susceptibility to stereotype messages emphasizing women's abilities was specific to the task reflecting the stereotype. 
Another important finding of the stereotype-threat literature is that stereotype messages also may have a positive impact on cognitive performance (see, e.g., Johns, Schmader, \& Martens, 2005; Shih et al., 1999; Walton \& Cohen, 2003). For example, Shih et al. found that Asian American women who were reminded of their Asian identity performed better on a math test than did controls. More recent studies have demonstrated that prior knowledge of the effects of stereotype messages can mitigate their influence on women's math performance (Johns et al., 2005).

The goal of the present research was to examine the degree to which men's and women's performance of a mental rotation task could be influenced by stereotype messages. Previous attempts at altering mental rotation performance through experiential factors have been problematic (for reviews, see Casey, 1996; Masters, 1998). For example, Sharps and colleagues found that gender differences on a mental rotation task diminished when the researchers eliminated mention of the spatial connotations of the task from the instruction set (Sharps, Price, \& Williams, 1994; Sharps, Welton, \& Price, 1993), and when they altered the task instructions to emphasize cognitive skills involved in stereotypical feminine versus masculine occupations (Sharps et al., 1994). Although promising, these results are difficult to interpret because the experimenters did not include control conditions. Thus, it is impossible to determine whether the performance shifts that were found by Sharps and colleagues were due to relative increases in women's performance, relative decreases in men's performance, or a combination of both.

In the present experiments, we examined the effects of a stereotype message (emphasizing female abilities) on men's and women's performance of a mental rotation task. Rather than utilize the traditional mental rotation paradigm involving rotations of objects (see, e.g., Shepard \& Metzler, 1971), we used a task that involved imagined rotations of the self (see Figure 1) (Presson, 1982; Wraga, Creem, \& Proffitt, 2000). Both classes of mental rotation are considered to be important for tasks of human spatial reasoning (Zacks, Vettel, \& Michelon, 2003). However, imagined self-rotations differ from imagined object rotations in that they require the transformation of a bodycentric versus objectcentric spatial frame of reference (Easton \& Sholl, 1995; Wraga, 2003). Imagined self-rotations are also unique in that they can have a social connotation when described in the context of perspective taking. Thus, the imagined self-rotation paradigm allowed us to manipulate the social connotations of the task, construing it as one of perspective taking (considered a strong female ability) rather than spatial cognition, its true domain.

Our study differed from others that have examined gender differences in mental rotation on another important factor. Previous studies have relied on participants' performance of the Vandenberg and Kuse (VK) (1978) mental rotation task, which consists of 20 trials completed within a set time frame. The VK test produces only a single score, which is a tally of the correct answers given. For our task, we recorded both accuracy and response time (RT) for 24 individual trials. This allowed a more fine-grained measure of mental rotation performance.

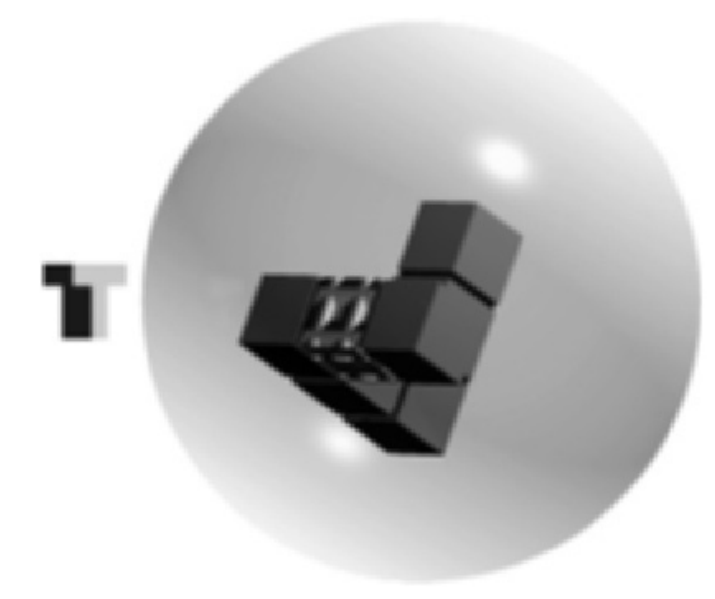

Figure 1. Sample stimuli used in the self-rotation task. Participants imagined rotating themselves to a location just behind the $T$ prompt. Then they judged whether or not the object's textured cube was visible from that new perspective. The correct answer for this trial is "no."

\section{EXPERIMENT 1}

The first study was designed to establish gender differences in men's and women's performance of our imagined self-rotation task. Like their imagined object-rotation counterparts (see, e.g., Linn \& Petersen, 1985), imagined rotations of the self that are performed in the picture plane do not yield gender differences (Creem, Wraga, \& Proffitt, 2001; Wraga et al., 2000), because they can be construed as simple, two-dimensional rotations. The present study involved a more difficult task that required imagined selfrotations in depth. Although this task had been studied previously (Wraga, Shephard, Church, Inati, \& Kosslyn, 2005), gender differences were not examined directly and were thus only noted anecdotally. We predicted that women would perform worse than men on the imagined self-rotation task.

\section{Method}

Participants. We recruited 20 right-handed individuals (10 females, 10 males; age: $M=21.8, S D=4.4$ ) from the Smith College community. Handedness was determined by the Edinburgh handedness scale (Oldfield, 1971). Participants were paid $\$ 5$ for their participation.

Materials. The stimuli were three-dimensional depictions of the multiarmed cube figures originally used by Shepard and Metzler (1971) and were rendered with Bryce 3-D software (MetaCreations, New York). Each object was depicted within a sphere. One of the inner cubes of each object was textured, and a three-dimensional Tshaped prompt appeared on the outside of the sphere (see Figure 1). We used 4 different objects that were rotated in increments of $65^{\circ}$, $100^{\circ}$, and $135^{\circ}$ in either the $x$ (frontal) or the $y$ (transverse) plane of rotation $($ total $=24)$. From the 24 stimuli, we created two orders of trials.

Stimuli were displayed on a Macintosh PowerBook G3 computer using PsyScope software (Cohen, MacWhinney, Flatt, \& Provost, 1993), which recorded responses and RTs. The visual images were $8.5 \mathrm{~cm}$ in diameter on average. As viewed by the participant on the computer monitor, this average corresponded to approximately $3.3^{\circ}$ of horizontal visual angle. 
Procedure and Design. First, a female experimenter administered written instructions on the computer monitor. Participants were asked to imagine rotating their bodies about the sphere until their eyes lined up behind the horizontal line of the $\mathrm{T}$ prompt, as if they were looking at the object through the T. Then they made either a "yes" or a "no" decision as to whether the interior textured cube would be visible from that new perspective. They were instructed to make these judgments as quickly and accurately as possible; thus, speed and accuracy were weighted equally.

The duration of each rotation trial was $12 \mathrm{sec}$. Within each set of trials, fixation points of 3-24 sec (in increments of $3 \mathrm{sec}$ ) were randomly interspersed, for a total duration of $468 \mathrm{sec}$. An equal number of "yes" and "no" responses appeared in each set of trials.

The participants performed two sets of trials with a short break in between. They responded by using their dominant hands to press one of two keys on the computer keyboard. The keys were covered with different textures to help distinguish them by touch.

Each set of trials occurred in a pseudorandom order with the following restrictions: The same response could occur only two times in succession, and the same rotation magnitude could be repeated only after all variations had appeared once. The order of trials within each set of rotations was kept constant across participants.

\section{Results and Discussion}

Women's error rates $(M=33 \% ; S E=.03)$ were significantly higher than men's $(M=21 \% ; S E=.03)$ on the imagined viewer-rotation task (see Figure 2A). A 2 (gender) $\times$ 3 (rotation magnitude) mixed measures ANOVA on mean percent error yielded main effects of gender $[F(1,18)=$ $10.73, p<.004]$ and rotation magnitude $[F(2,36)=23.87$, $p<.0001]$. We found no significant interactions. Linear contrasts performed on the rotation magnitude effect indicated that errors decreased from $65^{\circ}$ rotations to $100^{\circ}$ rotations $[t(19)=7.12, p<.0001]$ and increased from $100^{\circ}$ rotations to $135^{\circ}$ rotations $[t(19)=-4.17, p<.001]$.

The analysis of RTs yielded no difference between groups (see Figure 2B). ${ }^{1}$ A 2 (gender) $\times 3$ (rotation magnitude) mixed measures ANOVA on mean RTs yielded a main effect of rotation magnitude only $[F(2,36)=16.46$, $p<.0001]$ and no significant interactions. Linear contrasts indicated that errors decreased from $65^{\circ}$ rotations to $100^{\circ}$ rotations $[t(19)=4.87, p<.0001]$ and increased from $100^{\circ}$ rotations to $135^{\circ}$ rotations $[t(19)=-4.03, p<.001]$.

As expected, women performed worse on the imagined self-rotation task than did men. The absence of a significant interaction between gender and rotation magnitude indicated that the performance deficit was due to general factors rather than to women's difficulties with one class of rotation magnitude, per se. The V-shaped pattern we found across genders in both error and RT functions was similar to patterns that have been found in other imagined self-rotation studies (see, e.g., Wraga, 2003; Wraga et al., 2005). It has been previously attributed to the fact that performance is typically faster and more accurate with rotations that are more closely aligned with one of the major axes of the human body (e.g., $100^{\circ}$ ) than with those that are not (e.g., 65 $\left.5^{\circ} 135^{\circ}\right)$ (Wraga, 2003).

\section{EXPERIMENT 2}

Having verified that typical gender differences existed for the present imagined self-rotation task, we next exam-

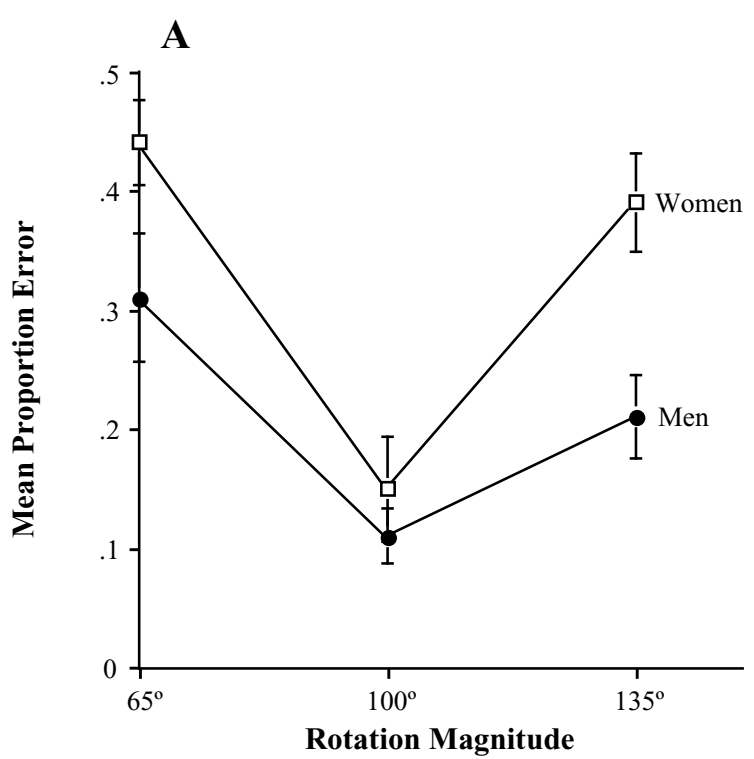

B

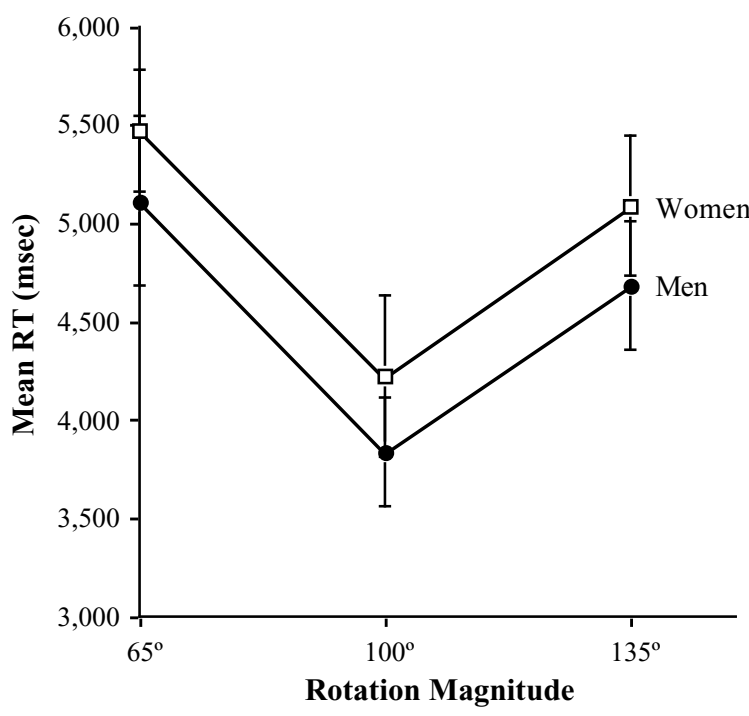

Figure 2. (A) Mean proportion error $( \pm S E)$ and (B) mean response times (RTs) and standard errors of the self-rotation trials for men and women as a function of rotation magnitude, Experiment 1.

ined the effects of a positive stereotype on women's performance of the task. We tested two groups of women. Prior to testing, the experimental group was informed that women perform better on imagined self-rotation tasks than do men because of their greater ease with perspective taking. The control group received neutral information. We hypothesized that performance in the experimental group would be improved in comparison with that of the controls.

\section{Method}

Participants. We recruited 30 right-handed female individuals (age: $M=19.2, S D=0.8$ ) from Smith College. Handedness was determined by the Edinburgh handedness scale (Oldfield, 1971). Participants received class research credit for their participation. 
Materials. The materials were identical to those in Experiment 1.

Procedure and Design. The procedure and design were identical to those in Experiment 1, with the following exceptions. Half of the participants were randomly assigned to the control group; the other half were assigned to the experimental group. Prior to receiving the task instructions, the control group read a neutral statement, and the experimental group read a statement that detailed how women perform better at this task than men (the stereotype condition; see Appendix). Both statements, adapted from Aronson et al. (1999), appeared as the first instruction screen on the computer monitor.

\section{Results and Discussion}

The error rates of the stereotype group $(M=28 \%$; $S E=0.01)$ were significantly lower than those of the control group $(M=34 \% ; S E=0.01)$ (see Figure $3 \mathrm{~A})$. A 2 (condition: stereotype, control) $\times 3$ (rotation magnitude) mixed measures ANOVA on mean percent error yielded main effects of condition $[F(1,28)=11.85, p<.002]$ and rotation magnitude $[F(2,56)=21.66, p<.0001]$. We found no significant interactions. Linear contrasts performed for the rotation magnitude effect indicated that errors decreased from $65^{\circ}$ rotations to $100^{\circ}$ rotations $[t(29)=6.71, p<.0001]$ and increased from $100^{\circ}$ rotations to $135^{\circ}$ rotations $[t(29)=-5.55, p<.0001]$.

The analysis of RTs yielded no difference between groups (see Figure 3B). A 2 (condition) $\times 3$ (rotation magnitude) mixed measures ANOVA on mean RTs yielded a main effect of rotation magnitude only $[F(2,56)=35.61, p<.0001]$ and no significant interactions. Linear contrasts indicated that errors decreased from $65^{\circ}$ rotations to $100^{\circ}$ rotations $[t(29)=8.82, p<.0001]$ and increased from $100^{\circ}$ rotations to $135^{\circ}$ rotations $[t(29)=-7.24, p<.0001]$.

We also directly compared the performance of women in the stereotype condition of Experiment 2 with that of men in Experiment 1 (neutral condition). As would be expected from the results of the previous experiment, we again found no difference between RTs across men and women. However, we did find a difference in errors. A 2 (gender) $\times 3$ (rotation magnitude) mixed measures ANOVA on mean errors yielded main effects of gender $[F(1,23)=6.99$, $p<.014]$ and rotation magnitude $[F(2,46)=17.77, p<$ $.0001]$, the latter of which reflected the V-shaped pattern found consistently. These findings suggest that, although the positive stereotype manipulation in Experiment 2 improved women's performance with respect to other women, mean errors $(28 \%)$ were still greater than those produced by men who were given neutral instructions in Experiment $1(21 \%)$. Given that there were some methodological differences in the two studies, comparisons across Experiments 1 and 2 are not fully warranted. However, such comparisons are suggestive and direct us toward future research designs that could more directly assess the strength of the stereotype message across gender.

\section{EXPERIMENT 3}

We next sought to determine whether the stereotype message regarding women's superior perspective-taking abilities could produce a negative effect on men's performance of imagined self-rotations. We tested two groups of men under
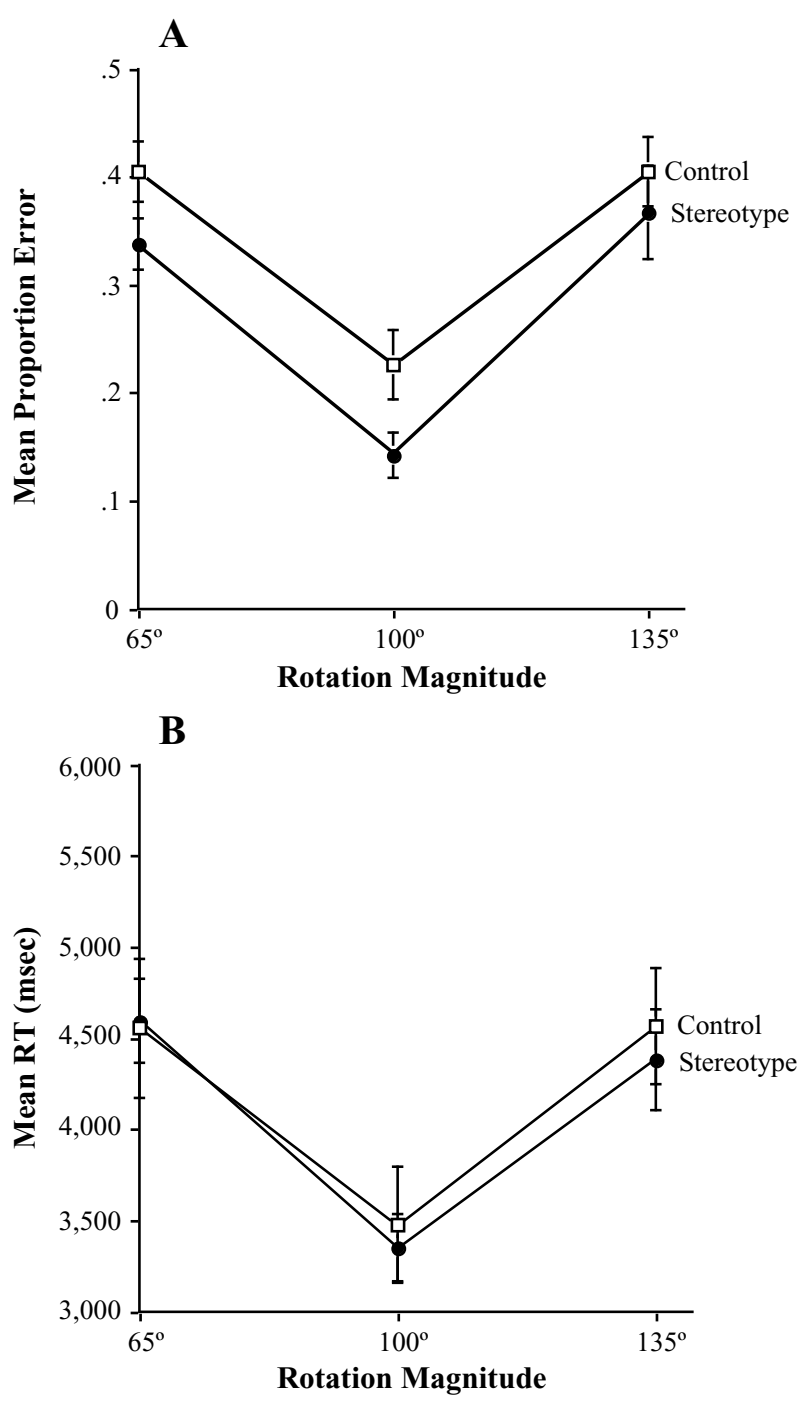

Figure 3. (A) Mean proportion error $( \pm S E)$ and (B) mean RTs and standard errors of the self-rotation trials for women in the control and stereotype groups as a function of rotation magnitude, Experiment 2.

experimental conditions identical to those in Experiment 2. We predicted that performance in the experimental group would be degraded in comparison with that of the controls.

\section{Method}

Participants. We recruited 20 right-handed male individuals (age: $M=25.1, S D=4.9$ ) from the Northampton, MA, community, 12 of whom were enrolled in a summer course at the University of Massachusetts, Amherst. Handedness was determined by the Edinburgh handedness scale (Oldfield, 1971). Participants were paid \$5 for their participation.

Materials. The materials were identical to those in Experiment 2.

Procedure and Design. The procedure and design were identical to those in Experiment 2.

\section{Results and Discussion}

Error rates of the experimental group $(M=33 \%$; $S E=$ 0.03 ) were significantly higher than those of the con- 
trol group $(M=20 \% ; S E=0.02)($ see Figure 4 A). A 2 (condition: stereotype, control) $\times 3$ (rotation magnitude) mixed measures ANOVA on mean percent error yielded main effects of condition $[F(1,18)=12.81, p<.002]$ and rotation magnitude $[F(2,36)=6.17, p<.005]$. We found no significant interactions. Linear contrasts performed for the rotation magnitude effect indicated that errors decreased from $65^{\circ}$ rotations to $100^{\circ}$ rotations $[t(19)=3.23$, $p<.004]$ and increased from $100^{\circ}$ rotations to $135^{\circ}$ rotations $[t(19)=-3.37, p<.003]$.

The analysis of RTs yielded no difference between groups (see Figure 4B). A 2 (condition) $\times 3$ (rotation magnitude) mixed measures ANOVA on mean RTs yielded a main effect of rotation magnitude only $[F(2,36)=3.12, p<.05]$ and no significant interactions. Linear contrasts indicated that errors decreased from $65^{\circ}$ rotations to $100^{\circ}$ rotations $[t(19)=1.73, p<.101]$ and increased from $100^{\circ}$ rotations to $135^{\circ}$ rotations $[t(19)=-3.80, p<.001]$.

We also directly compared the performance of men in the experimental condition with women's performance in Experiment 1. We again found no difference between RTs across men and women. However, more importantly, we also found no difference in errors. A 2 (gender) $X$ 3 (rotation magnitude) mixed measures ANOVA on mean errors yielded a main effect of rotation magnitude only $[F(2,36)=16.34, p<.0001]$, which reflected the V-shaped pattern found consistently. The effect of gender was not significant ( $p=.919)$, nor were there any significant interactions. Differences in methodological procedures across the two experiments preclude a strong interpretation of this finding. However, exposure to a positive stereotype message about women's ability (that compared them positively with men) prior to testing in Experiment 3 appears to have rendered men's performance on a mental rotation task indistinguishable from that of women.

\section{GENERAL DISCUSSION}

Our research demonstrates that the gender gap in performance of a mental rotation task can be altered by exposing participants to a stereotype message. Experiment 1 revealed a significant performance gap favoring men on an imagined self-rotation task. In Experiment 2, women's performance in the task improved significantly after exposure to a positive stereotype. In contrast, Experiment 3 revealed that men's performance was significantly degraded when the same stereotype was invoked. These findings present clear-cut evidence of altered mental rotation performance via an experiential factor. This study contributes to research demonstrating that gender differences on spatial tasks can be reduced through experiential factors (Baenninger \& Newcombe, 1989; Connor, Schackman, \& Serbin, 1978; Connor \& Serbin, 1985; Koslow, 1987; Willis \& Schaie, 1988). The malleability of men's and women's performance in these studies suggests that cognitive ability associated with at least some mental rotation tasks is not attributable solely to biological factors, but is also susceptible to environmental influences.
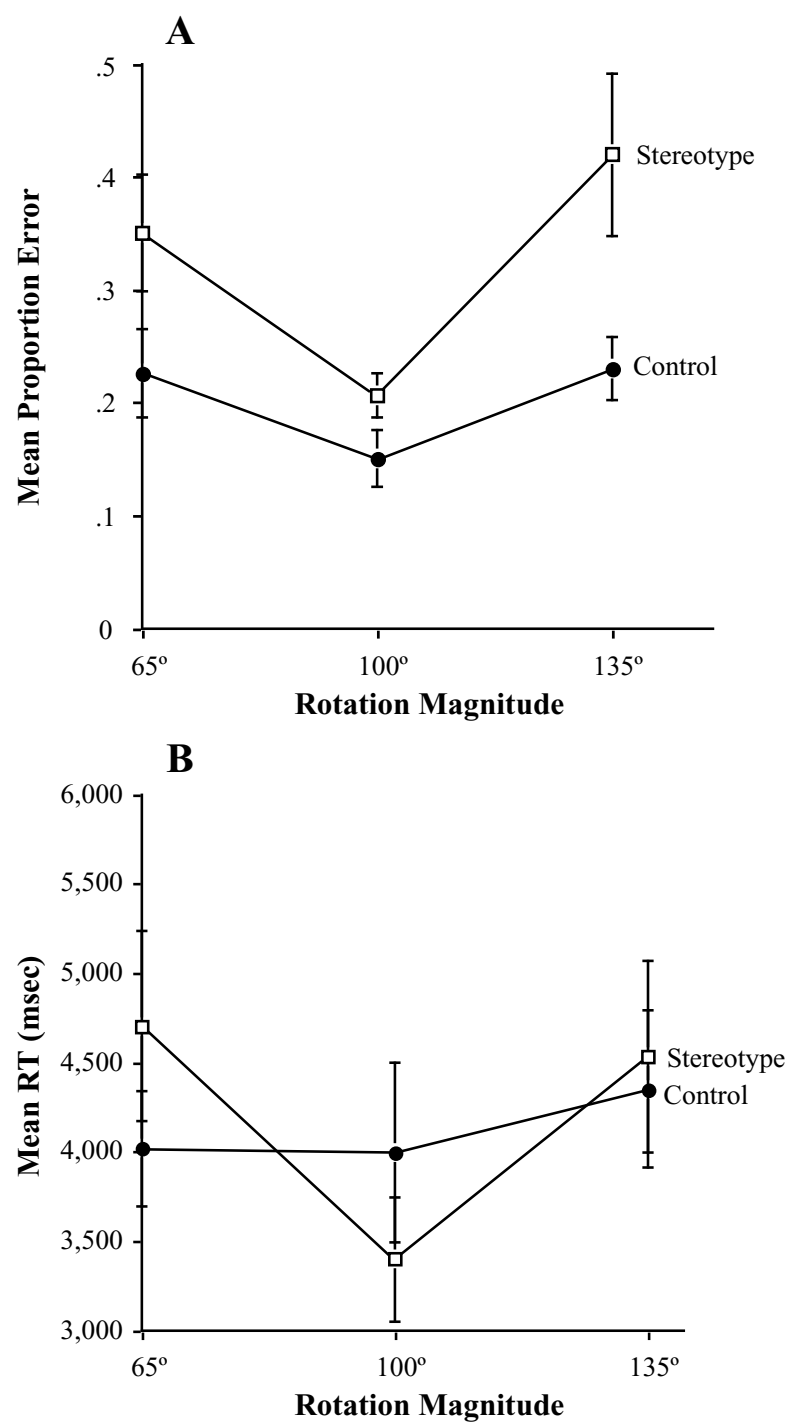

Figure 4. (A) Mean proportion error $( \pm S E)$ and (B) mean RTs and standard errors of the self-rotation trials for men in the control and stereotype groups as a function of rotation magnitude, Experiment 3.

One might argue that the present findings were due merely to participants' responses to the demand characteristics of the experiments. After all, our stereotype message included specific information on speed and accuracy patterns associated with the self-rotation task. However, in both Experiments 2 and 3, shifts in performance were reflected in participants' accuracy scores only, despite the fact that RTs were equally vulnerable to potential manipulation. Men who were exposed to the stereotype message did make more errors than did controls, but they did not perform relatively slower, and women who were exposed to the stereotype message did not speed up their mental rotation judgments. These findings suggest that participants did not consciously alter their performance on demand; rather, they became vulnerable to the stereotype message. 
Such criticisms notwithstanding, the findings still demonstrate an important fact: Mental rotation performance is affected by situational factors.

One of the intriguing outcomes of exposure to the stereotype message was the relative shift in performance (either improved or degraded) that was found. Whereas men's performance accuracy in Experiment 3 fell by an average of $12 \%$ in comparison with that of controls, women's performance in Experiment 2 improved by only $6 \%$ in comparison with that of controls. Under the present paradigm, it was not possible to discern the precise factors underlying shifts in performance, or whether the factors underlying men's degraded performance were identical to those involved in improving women's performance. However, a within-gender precedent exists for this differential response pattern. Cadinu, Maass, Frigerio, Impagliazzo, and Latinotti (2003) found that the performance gains of women who were exposed to a positive stereotype about women's mathematical abilities and compared with controls were only about half of the performance decrements found in women who were exposed to a negative stereotype and compared with controls. These findings suggest that it is easier to undermine cognitive performance via situational factors than it is to improve it. However, a subsequent study using similar stereotype messages and performed with women only revealed roughly equivalent positive and negative performance shifts (Wraga, Helt, Jacobs, $\&$ Sullivan, in press). In the study, the stereotype messages were altered slightly in an attempt to increase the neutrality of the control condition. This change had little effect on performance. The error rate differential for the positive group compared with the control group was slightly higher $(8 \%)$ than that of Experiment 2 of the present study. However, the error rate differential for those in the negative condition compared with controls was slightly lower than the positive-control error differential $(6 \%)$, which is a reduction of one half from the results of Experiment 3 of the present study. These findings suggest that the imbalance in relative performance shifts in the present study may be due to individual-subject variation. This issue warrants further empirical investigation.

These studies add to the growing number of those demonstrating that nonstigmatized groups, such as White men, are susceptible to negative stereotype messages (e.g., Aronson et al., 1999; Brown \& Josephs, 1999; Leyens et al., 2000). The degraded performance of men in the experimental group of Experiment 3 was indistinguishable from that of women from the baseline group of Experiment 1 . Moreover, the fact that our stereotype message was false but still had an impact on men's cognitive performance was also significant. Leyens et al. found that men who were exposed to a stereotype concerning women's superiority at affective processing showed selective performance deficits for judgments of affective words, but not for nonaffective judgments. The results of Experiment 3 indicate that a stereotype message can affect a task even if it is merely construed as reflecting the stereotype, but is not an accurate depiction thereof.
In summary, we demonstrated that men's and women's performance of imagined self-rotations was susceptible to sociocultural stereotypes. These findings indicate that the gender gap in mental rotation ability-for at least some tasks - can be influenced by experiential factors. Thus, performance differences may be less biologically entrenched than previously has been thought.

\section{REFERENCES}

Aronson, J., Lustina, M. J., Good, C., Keough, K., Steele, C. M., \& Brown, J. (1999). When White men can't do math: Necessary and sufficient factors in stereotype threat. Journal of Experimental Social Psychology, 35, 29-46.

Baenninger, M., \& Newcombe, N. (1989). The role of experience in spatial test performance: A meta-analysis. Sex Roles, 20, 327-344.

Brown, R. P., \& Josephs, R. A. (1999). A burden of proof: Stereotype relevance and gender differences in math performance. Journal of Personality \& Social Psychology, 76, 246-257.

Cadinu, M., MaAss, A., Frigerio, S., Impagliazzo, L., \& Latinotti, S. (2003). Stereotype threat: The effect of expectancy on performance. European Journal of Social Psychology, 33, 267-285.

Campos, A., Pérez-Fabello, M. J., \& Gómez-Juncal, R. (2004). Gender and age differences in measured and self-perceived imaging capacity. Personality \& Individual Differences, 37, 1383-1389.

Casey, M. B. (1996). Gender, sex, and cognition: Considering the interrelationship between biological and environmental factors. Learning \& Individual Differences, 8, 39-53.

COHEN, J., \& CoHEN, P. (1983). Applied multiple regression/correlation analyses for the behavioral sciences (2nd ed.). Hillsdale, NJ: Erlbaum.

Cohen, J. D., MacWhinney, B., Flatt, M., \& Provost, J. (1993). PsyScope: An interactive graphic system for designing and controlling experiments in the psychology laboratory using Macintosh computers. Behavior Research Methods, Instruments, \& Computers, 25, 257-271.

Connor, J. M., Schackman, M., \& Serbin, L. A. (1978). Sex-related differences in response to practice on a visual-spatial test and generalization to a related test. Child Development, 49, 24-29.

Connor, J. M., \& Serbin, L. A. (1985). Visual-spatial skill: Is it important for mathematics? Can it be taught? In S. F. Chipman, L. R. Brush, \& D. M. Wilson (Eds.), Women and mathematics: Balancing the equation (pp. 151-174). Hillsdale, NJ: Erlbaum.

Creem, S. H., Wraga, M., \& Proffitt, D. R. (2001). Imagining physically impossible self-rotations: Geometry is more important than gravity. Cognition, 81, 41-64.

EAston, R. D., \& Sholl, M. J. (1995). Object-array structure, frames of reference, and retrieval of spatial knowledge. Journal of Experimental Psychology: Learning, Memory, \& Cognition, 21, 483-500.

Feingold, A. (1988). Cognitive gender differences are disappearing. American Psychologist, 43, 95-103.

Geary, D. C. (1995). Sexual selection and sex differences in spatial cognition. Learning \& Individual Differences, 7, 289-301.

Johns, M., Schmader, T., \& Martens, A. (2005). Knowing is half the battle: Teaching stereotype threat as a means of improving women's math performance. Psychological Science, 16, 175-179.

Kimura, D., \& Hampson, E. (1994). Cognitive pattern in men and women is influenced by fluctuations in sex hormones. Current Directions in Psychological Science, 3, 57-61.

KosLow, R. E. (1987). Sex-related differences and visual-spatial mental imagery as factors affecting symbolic motor skill acquisition. Sex Roles, 17, 521-527.

LEVY, B. (1996). Improving memory in old age through implicit selfstereotyping. Journal of Personality \& Social Psychology, 71, 10921107.

Leyens, J.-P., Désert, M., Croizet, J.-C., \& Darcis, C. (2000). Stereotype threat: Are lower status and history of stigmatization preconditions of stereotype threat? Personality \& Social Psychology Bulletin, 26, 1189-1199.

Linn, M. C., \& Petersen, A. C. (1985). Emergence and characterization 
of sex differences in spatial ability: A meta-analysis. Child Development, 56, 1479-1498.

Masters, M. S. (1998). The gender difference on the Mental Rotations Test is not due to performance factors. Memory \& Cognition, 26, 444-448.

Masters, M. S., \& SANDERS, B. (1993). Is the gender difference in mental rotation disappearing? Behavior Genetics, 23, 337-341.

OLDFIELD, R. C. (1971). The assessment and analysis of handedness: The Edinburgh inventory. Neuropsychologia, 9, 97-113.

Presson, C. C. (1982). Strategies in spatial reasoning. Journal of Experimental Psychology: Learning, Memory, \& Cognition, 8, 243-251.

RiPley, A. (2005, March 7). Who says a woman can't be Einstein? Time, pp. $50-60$.

Sharps, M. J., Price, J. L., \& Williams, J. K. (1994). Spatial cognition and gender: Instructional and stimulus influences on mental image rotation performance. Psychology of Women Quarterly, 18, 413-425.

Sharps, M. J., Welton, A. L., \& Price, J. L. (1993). Gender and task in the determination of spatial cognitive performance. Psychology of Women Quarterly, 17, 71-83.

Shepard, R. N., \& Metzler, J. (1971). Mental rotation of threedimensional objects. Science, 171, 701-703.

Shin, M., PitTinsky, T. L., \& Ambady, N. (1999). Stereotype susceptibility: Identity salience and shifts in quantitative performance. Psychological Science, 10, 80-83.

Spencer, S. J., Steele, C. M., \& Quinn, D. M. (1999). Stereotype threat and women's math performance. Journal of Experimental Social Psychology, 35, 4-28.

Steele, C. M. (1997). A threat in the air: How stereotypes shape intellectual identity and performance. American Psychologist, 52, 613-629.

Steele, C. M., \& Aronson, J. (1995). Stereotype threat and the intellectual test performance of African Americans. Journal of Personality \& Social Psychology, 69, 797-811.

Steele, C. M., Spencer, S. J., \& Aronson, J. (2002). Contending with group image: The psychology of stereotype and social identity threat. In M. P. Zanna (Ed.), Advances in experimental social psychology (Vol. 34, pp. 379-440). San Diego: Academic Press.
VandenberG, S. G., \& Kuse, A. R. (1978). Mental rotations, a group test of three-dimensional spatial visualization. Perceptual \& Motor Skills, 47, 599-604.

Voyer, D., Voyer, S., \& BRYden, M. P. (1995). Magnitude of sex differences in spatial abilities: A meta-analysis and consideration of critical variables. Psychological Bulletin, 117, 250-270.

Walton, G. M., \& Cohen, G. L. (2003). Stereotype lift. Journal of Experimental Social Psychology, 39, 456-467.

Willis, S. L., \& Schaie, K. W. (1988). Gender differences in spatial ability in old age: Longitudinal and intervention findings. Sex Roles, 18, 189-203.

WraGa, M. (2003). Thinking outside the body: An advantage for spatial updating during imagined versus physical self-rotation. Journal of Experimental Psychology: Learning, Memory, \& Cognition, 29, 993-1005.

Wraga, M., Creem, S. H., \& Proffitt, D. R. (2000). Updating displays after imagined object and viewer rotations. Journal of Experimental Psychology: Learning, Memory, \& Cognition, 26, 151-168.

Wraga, M., Helt, M., Jacobs, E., \& Sullivan, K. (in press). Neural basis of stereotype-induced shifts in women's mental rotation performance. Social Cognitive \& Affective Neuroscience.

Wraga, M., Shephard, J. M., Church, J. A., Inati, S., \& Kosslyn, S. M. (2005). Imagined rotations of self versus objects: An fMRI study. Neuropsychologia, 43, 1351-1361.

ZACKs, J. M., VetTel, J. M., \& Michelon, P. (2003). Imagined viewer and object rotations dissociated with event-related fMRI. Journal of Cognitive Neuroscience, 15, 1002-1018.

\section{NOTE}

1. Because the number of participants in each group was small, the analyses were capable of detecting only large effect sizes (Cohen \& Cohen, 1983). It is possible, therefore, that differences in RT might be detectable with a larger number of participants. This issue can be addressed with further research.

\section{APPENDIX}

\section{Wording for Control Condition, Experiments 2 and 3}

The ability to imagine rotating one's perspective in space is critical to performance in many important subjects in college. Yet surprisingly little is known about the mental processes underlying this ability. The goal of this research is to examine what makes some people better at the imagined self-rotation task than others. Your performance will be compared to that of other students across the nation.

\section{Wording for Experimental (Stereotype) Condition, Experiments 2 and 3}

The ability to imagine rotating one's perspective in space is critical to performance in many important subjects in college. Yet surprisingly little is known about the mental processes underlying this ability. The goal of this research is to examine what makes some people better at this task than others. Our previous research has shown that female students consistently outperform male students in this task: They usually respond faster and make fewer errors. As you may know, a large body of research has found that women typically have more experience than men at taking others' perspectives. It is possible that this advantage underlies superior performance on the imagined self-rotation task. The research in which you are participating is designed to better understand this phenomenon. Your performance will be compared to that of other students across the nation. 